\title{
An Efficient Method for the Sulfonylation of Aromatic Rings with Arene/Alkane Sulfonic Acid by Using $\mathrm{P}_{2} \mathrm{O}_{5} / \mathrm{SiO}_{2}$ under Heterogeneous Conditions ${ }^{\S}$
}

\author{
BiBi Fatemeh Mirjalili, ${ }^{\star}$ Mohamad Ali Zolfigol, ${ }^{\ddagger}$ Abdolhamid Bamoniri, ${ }^{\ddagger}$ and Leila Khazdooz \\ Department of Chemistry: College of Science, Lazd Lniversitvi Yazd 89195-711, Iran \\ ${ }^{+}$Department of Chemistry, College of Science, Bu-1/i Sina Lniversity, P.O. Box 1135, Hamadan 6517t, Iran \\ -Department of Chemistry, College of Science, Kashan University, Kashan 51167, Iran \\ Received Harch 19, 2003
}

Key Words : Sulfony lation. Sulfones. Di-phosphonıs pentoxide

Aryl sulfones are of great use in organic synthesis and industry. ${ }^{1.2}$ Diaryl sulfones are important drugs active against leishmaniasis. malaria. and infections in patients with AIDS discoid lupus erythematosus. ${ }^{3,4}$

Diaryl. aryl/alkyl sulfones can be synthesized by conventional Friedel-Crafts type sulfonylation of aromatics by sulfonyl halides in the presence of Lewis acids such as $\mathrm{AlCl}_{3}, \mathrm{BF}_{3}$, triflic acid/BiCls. Zn-exchanged zeolites, Fe(III)-exchanged montmorillonite clay, scandium and lanthanide (III) salts, ${ }^{\text {" }}$ $\mathrm{Cu}(\mathrm{OTf})_{2}$ or $\mathrm{Sn}(\mathrm{OTf})_{2}{ }^{\circ}$ and etc. Recently. Olah and coworkers have reported the sulfonylation of arenes by sulfonic acids in the presence of Nafion-H. ${ }^{7}$ Very recently. we anong many others have demonstrated that heterogeneous reagent systems have many advantages such as simple experimental procedures. mild reaction conditions and mininization of chenical wastes as compared to the homogeneous counterparts. ${ }^{8}$ In this article. we report an efficient preparation of aromatic sulfones directly from arene or alkane sulfonic acid with $\mathrm{P}_{2} \mathrm{O}_{5} / \mathrm{SiO}_{2}$ system. Literature survey shows that phosphorus pentoxide (phosphoric anhydride) can be used as a dehydrating agent for the formation of anhydride from two molecules of an ordinary acid. ketenimines from amides. vinyl ethers from acetals. nitriles from amides, ${ }^{9}$ anides from oximes. ${ }^{11}$ phenolic esters from carboxylic acids ${ }^{11}$ and so on. On the basis of the above mentioned ability of $\mathrm{P}_{2} \mathrm{O}_{5}$ we decided to use it embedded on silica-gel for the production of sulfones via direct sulfony lation of aronatic rings.

Preparation of symmetric and unsymmetric aromatic sulfones was achieved in moderate to good yields (50-95\%) vic Friedel-Crafts type sulfonylation of arenes with various sulfonic acids (Scheme 1).

$$
\begin{array}{ll}
\mathrm{R}_{1}-\mathrm{SO}_{3} \mathrm{H}+\mathrm{Ar}-\mathrm{H} \quad \stackrel{\mathrm{P}_{2} \mathrm{O}_{5} / \mathrm{SiO}_{2}(\mathrm{w} / \mathrm{w} 75 \%)}{\text { reflux }} \mathrm{R}_{1} \mathrm{SO}_{2} \mathrm{Ar} \\
\mathrm{R}_{1}=\text { alkyl or aryl }
\end{array}
$$

Scheme 1

The sulfonylation reactions were carried out by refluxing a stirred mixture of the corresponding arene or alkane sulfonic

\footnotetext{
Dedicated to our teacher, professor Abdolhossein Rustaivan on the occasion of his seventyfifth birthday

*Corresponding author. E-mail: fmirialiliấyazduniac.ir
}

acid and excess dried arene in the presence of $\mathrm{P}_{2} \mathrm{O}_{5}-\mathrm{SiO}_{2}$ (w/w $75 \%$ ). The arene acts as both substrate and solvent. Activated arenes such as anisole and mesitylene afforded the corresponding sulfones in excellent yields (90-95\%). The yield of the corresponding sulfones from benzene was low $(50-52 \%)$ due to its lower boiling point. The present method provides an easy and fast approach to sulfones without any by-product. Sulfonylations of anisole. cumene. toluene and bromobenzene afforded para substituted sulfones as the major product indicating that the reaction belongs to electrophilic aromatic substitutions (Table 1). In contrast to the reported method by Olah et $a l .{ }^{7}$ the present method does not require a Dean-Stark trap for removing azeotropic removal of water.

In conclusion, the cheapness and the availability of the reagents, and good yields would make this method attractive for the large-scale operations. We believe that our new process would be an important addition to the existing methods.

\section{Experimental Section}

General. chemicals such as various arenes. $p$-toluene sulfonic acid. benzene sulfonic acid. methane sulfonic acid. silica gel and di-phosphorus pentoxide were purchased from Fluka. Merck and Aldrich Chemical Companies. The sulfonylation products were characterized by comparison of their spectral (IR. ${ }^{1} \mathrm{H}-\mathrm{NMR}$ ), TLC and plyysical data with authentic samples. ${ }^{6}$

Typical procedure for the preparation of sulfones: preparation of anisyl tolyl sulfone. To a mixture of toluene4-sulfonic acid monolydrate $(0.6 \mathrm{~g} .3 .1 \mathrm{mmole})$ and dry anisole $(5 \mathrm{~mL})$ was added $\mathrm{P}_{2} \mathrm{O}_{5} / \mathrm{SiO}_{2}(\mathrm{w} / \mathrm{w} 75 \%, 1.2 \mathrm{~g})$. The solution was refluxed continuously with stirring for 30 minutes. The reaction mixture was filtered and washed with $10 \% \mathrm{NaHCO}_{3}$ solution to remove unreacted sulfonic acid. After washing with water and drying with anhydrous $\mathrm{Na}_{2} \mathrm{SO}_{4}$. excess anisole was distilled off by vacuum and the residue was recry stalized with $n$-hexane to afford anisyl tolyl sulfone as a white crystalline solid $(0.75 \mathrm{~g}, 90 \%), \mathrm{mp}=79-80$ ${ }^{\circ} \mathrm{C}, \mathrm{R}_{\mathrm{f}}=0.5$ (50:50 ether/petroleum ether).

Acknowledgment. Financial support made by the research affairs, Yazd University. Yazd. Iran and also Bu-Ali Sina University, Hamadan. Iran, is gratefully acknowledged. 
Table 1. Sulfonylation of aromatic rings by aryl or alkyl sulfonic acids in presence of $\mathrm{P}_{2} \mathrm{O}_{5} / \mathrm{S}_{1} \mathrm{O}_{2}(\mathrm{w} / \mathrm{w} 75 \%)$

\begin{tabular}{|c|c|c|c|c|c|}
\hline Entry & Sulfonic acid & arene & Time (mir) & Yield (\%) (o:mp) & sulfone \\
\hline 1 & $-11>\mathrm{s}$ & Toluene & 90 & $\begin{array}{c}80 \\
(13: 0: 87)\end{array}$ & \\
\hline 2 & & benzene & 105 & 50 & \\
\hline 3 & & Mesitylene & 30 & 85 & \\
\hline 4 & & bromobenzene & 90 & $\begin{array}{c}60 \\
(20: 10: 70)\end{array}$ & \\
\hline 5 & & anisole & 30 & $\begin{array}{c}90 \\
(34: 0: 66)\end{array}$ & \\
\hline 6 & & Cumene & 60 & 80 & \\
\hline 7 & & Toluente & 90 & $\begin{array}{c}85 \\
(25: 0: 75)\end{array}$ & \\
\hline 8 & & bromobenzene & 75 & $\begin{array}{c}65 \\
(20: 10: 70)\end{array}$ & \\
\hline 9 & & benzene & 90 & 52 & \\
\hline 10 & & anisole & 30 & $\begin{array}{c}95 \\
(45: 0: 55)\end{array}$ & \\
\hline 11 & & Cumene & 30 & 85 & \\
\hline 12 & & mesitylente & 30 & 90 & \\
\hline 13 & $\mathrm{CH}_{3}-\mathrm{SO}_{3} \mathrm{H}$ & mesitylene & 60 & 55 & \\
\hline 14 & & anisole & 30 & $\begin{array}{c}60 \\
(30: 10: 60)\end{array}$ & \\
\hline 15 & & Coumente & 60 & 50 & \\
\hline
\end{tabular}

\section{References}

1. (a) Jensen. F. R.: Goldman. G. In Friedet-Crafts and Retated Reaction: Olah. G. Ed: Wiley Intrscience: New York. 1964: VIII. pp 1319-1367. (b) Simpkins. N. S. Sulfones in Organic Sinthesis: Pergamon Press: Oxford. 1993.

2. Roy. K. M. In Lllmam s Encyctopedia of Indtustrat Chentistry: Gerhart. W. Ed.: VCH: Weinheim. 1985: VA 25. pp 487-501."

3. Hastings. R. C.: Franzblau. S. G. Amm. Ra? Phammacol. Toxicol. $1966,28,231$.

4. Wozel. G. Iht. J. Denmatol. 1989. 28, 17.

5. Frost. C. G.: Hartlev. I. P: Griftin. D. Tetrahedron Lett. 2002 , t3. 4789 .

6. Singh. R. P.: Kamble. R. M.: Chandra. K. L.: Saravanane. P.: Singh. V. K. Tetratiedron 2001, 57.241.
7. Olah. G. A.; Mathew. T.: Parakash. G. K. S. Chem Commun 2001. 1969

8. (a) Zoltigol. M. A. Tetrahedron 2001. 57. 9509 and other our reterences cited thereit1. (b) Zolfigol. M. A.: Torabi. M: Mallakpour. S. E. Tetrahedron 2001. 57. 8381. (c) Zoltigol. M A; Zebarjadian, M. H: Chehardoli. G.; Mallakpour. S. E.: Shamsipur. M. Tetrahedron 2001. 57. 1627. (d) Zolfigol, M. A.: Bamonir, A. Sylen 2002, 1621. (e) Zolfigol. M. A.; GhorbaniChoghamarani. A.: Hazarkhani. H. Swlett 2002. 10022. (f) Zolfigol. M. A.: Madrakiant. E.: Ghaemi. E.: Mallakpour. S. E. Synlett 2002. 1633.

9. March. J. Adranced Organic Chemistry 3rd Ed.: John Wiley: New York, 1985: p 904.

10. Eaton. C. L. J. Ong Chent 1973, 38, 4071

11. Eshghi. H.: Ratei. M.: Karimi. M. H. Swhh Commm 2001. 31. 771 